\title{
DEMOCRACIA: UMA OBRA HUMANA ACABADA?
}

Weslei Trevizan Amâncio ${ }^{1}$

Gustavo Biasoli Alves ${ }^{2}$

\begin{abstract}
RESUMO: O presente artigo objetiva analisar algumas das principais características da democracia à luz dos conceitos, valores e propostas presentes em Alfio Mastropaolo, Robert Dahl e Simon Schwartzman, com a seguinte problematização: podemos considerar a democracia uma obra humana que teria encontrado seu esgotamento, podendo ser considerada devidamente acabada? Para tanto, destacamos algumas das principais questões que tangenciam as reflexões e análises dos autores sobre o tema. Em seguida, realizamos comparações entre os elementos conceituais, valorativos e propositivos à democracia compartilhados. Neste processo, diante das análises e reflexões dos autores, compreende-se que é fundamentalmente depositado à democracia, por ser uma obra humana, aspirações de diversos significados, interesses, intenções, paixões, sendo, portanto, permeada por imperfeições no seu exercício. Por fim, pode-se inferir que o povo deve ser parte da construção para que um regime seja caracterizado como democrático e, em especial nesse processo, compreender que a democracia longe de ser uma obra acabada, de ter se esgotado, está em constante modificação, portanto, inacabada.
\end{abstract}

Palavras-chave: Democracia; Dahl; Mastropaolo; Schwartzman.

\section{DEMOCRACY: A FINISHED HUMAN WORK?}

\begin{abstract}
:
The

presentarticleaimstoanalyze

some ofthemaincharacteristicsofdemocracy in the light oftheconcepts, values andproposalspresent in AlfioMastropaolo, Robert Dahl and Simon Schwartzman, withthefollowingproblematization: wecanconsiderdemocracy

humanworkthatwouldhavefound its exhaustion, can it beconsideredproperlyfinished? Therefore, wehighlight some ofthemainissuesthattouchupontheauthors' reflectionsandanalyzesonthesubject. Next, wemakecomparisonsbetweenthe conceptual, valueandpropositionalelementsofshareddemocracy. In thisprocess, in the face oftheanalyzesandreflectionsoftheauthors, it isunderstoodthat fundamental aspirationsofdifferentmeanings, interests, intensions, passionsand, therefore, permeatedbyimperfections in theirexercise are fundamentallydepositedwithdemocracy. Finally, it canbeinferredthatthepeople must bepartoftheconstruction for a regime tobecharacterized as democratic, andespecially in thisprocess, tounderstandthatdemocracy, farfrombeing a finishedwork, hasbeenexhausted, isconstantlychanging, therefore, unfinished.
\end{abstract}

\footnotetext{
${ }^{1}$ Graduado em Serviço Social - Unespar/Fecea, Mestre em Ciências Sociais - Unioeste/Toledo. Assistente Social na UTFPR - Campus Londrina. Contato: wesleiamancio@utfpr.edu.br

${ }^{2}$ Graduado em Ciências Sociais e Mestre em Sociologia - Unesp/Araraquara. Doutor em Ciência Política UFRGS. Professor Associado da Unioeste. Contato: gbiasoli@uol.com.br

Programas de Pós-Graduação em Ciências Sociais e Filosofia - UNIOESTE - Rua da Faculdade 645. Toledo - PR. CEP 85.903-000 Email: revistaalamedas@gmail.com
} 
Keywords: Democracy; Dahl; Mastropaolo; Schwartzman.

\section{INTRODUÇÃO}

A proposição deste artigo está relacionadaa leituras, análises, debates e provocações construídas e compartilhadas na realização da disciplina Democracia, Participação e Políticas Públicas, do Programa de Mestrado em Ciências Sociais da UNIOESTE - Campus Toledo.

Diante disso, o objetivo estruturado é analisar algumas das principais características da democraciaà luz dos conceitos, valores e propostas presentes em Alfio Mastropaolo, Robert Dahl e Simon Schwartzman - autores trabalhados nas referidas disciplinas - com a seguinte problematização: podemos considerar a democracia uma obra humana que teria encontrado seu esgotamento, podendo ser considerada devidamente acabada?

A final, o que é democracia? É possível defini-la? Existe um modelo a ser seguido? Como deve ser tratada? Quais fatos sociais, políticos e culturais se relacionam menos ou mais, são mais ou menos determinante para o desenvolvimento da democracia? A participação do povo é essencialmente necessária para a sua realização? O modelo representativo é suficiente? Ou, pelo contrário, podemos falar que a democracia se esgotou?

Essas são questões que orbitam as reflexões e análise dos autores, as quais ajudam-nos a pensar sobre essa forma de organização humana e contribuem diretamente para uma resposta a principal problematização elencada. Neste processo, não se pode perder de vista que a trajetóriada democracia é permeada pordistintos significados, expressões, particularidades, interesses, diante de cada período histórico.

Assim, a fim de estruturar as proposições presentes neste artigo, destacamos, ainda que de forma sucinta, fecundas contribuições de algumas das principais categorias de análises presentes em obras de relevância de cada um dos autores citados.

Em seguida, realizamos algumas comparações entre os elementos conceituais, valorativos e propositivos à democracia compartilhados. Por fim, tecemos algumas considerações, com o intuito de contribuir com o debate e a análise da democracia, 
dando ênfase no confronto entre as potencialidades e limites presentes no que se entende hoje por ser a sua versão moderna.

\section{ROBERT DAHL: A POLIARQUIA COMO CONCEITO DE ANÁLISE}

Dahl (1997) defende que nenhuma democracia existente se aproximou do ideal democrático. Em termos objetivos podemos deduzir que as democracias produzidas são projetosincompletos. Desta forma, oteórico denomina os regimes democráticos experimentados de poliarquias.

\footnotetext{
"As poliarquias podem ser pensadas então como regimes relativamente, mas incompletamente, democratizados, ou, em outros termos, as poliarquias são regimes que foram substancialmente popularizados e liberalizados, isto é, fortemente inclusivos e amplamente abertos à contestação pública" (DAHL, 1997, p. 31).
}

O problema da democratização está relacionado com a ampliação da competição e participação. O ponto chave da democracia é o governo possuir condições e recursos para responder às preferências de seus cidadãos, devendo considerá-los politicamente iguais. Para tanto, os cidadãos devem ter três condições básicas - a oportunidade de: (i) formular suas preferências; (ii) expressar suas preferências a seus concidadãos e ao governo, seja em ação individual ou coletiva; e (iii) ter a suas preferências igualmente consideradas na conduta do governo (DAHL, 1997, p. 26).

Para que essas três oportunidades efetivamente possam existir a um grande número de pessoas do Estado-nação, as instituições da sociedade devem oferecer ao menos oito garantias. Abaixo, apresentamos quadro desenhado pelo autor em que denomina ser os "requisitos de uma democracia para um grande número de pessoas" (DAHL, 1997, p. 27):

\begin{tabular}{|l|l|}
\hline Para a oportunidade de: & $\begin{array}{l}\text { São necessárias as seguintes garantias } \\
\text { institucionais: }\end{array}$ \\
\hline I. Formular preferências & 1. Liberdade de formar e aderir a organizações \\
\hline
\end{tabular}




\begin{tabular}{|l|l|}
\hline & $\begin{array}{l}\text { 2. Liberdade de expressão } \\
\text { 3. Direito de voto } \\
\text { 4. Direito de líderes políticos disputarem apoio } \\
\text { 5. Fontes alternativas de informação }\end{array}$ \\
\hline II. Exprimir preferências & $\begin{array}{l}\text { 1. Liberdade de formar e aderir a organizações } \\
\text { 2. Liberdade de expressão } \\
\text { 3. Direito de voto } \\
\text { 4. Elegibilidade para cargos políticos } \\
\text { 5. Direito de líderes políticos disputarem apoio } \\
\text { 6. Fontes alternativas de informação } \\
\text { 7. Eleições livres e idôneas }\end{array}$ \\
\hline III. Ter preferências igualmente & $\begin{array}{l}\text { 1. Liberdade de formar e aderir a organizações } \\
\text { 2. Liberdade de expressão } \\
\text { 3. Direito de voto } \\
\text { 4. Elegibilidade para cargos públicos } \\
\text { 5. Direito de líderes políticos disputarem apoio } \\
\text { 5a. Direito de líderes políticos disputarem } \\
\text { votos } \\
\text { 6. Fontes alternativas de informação } \\
\text { 7. Eleições livres e idôneas } \\
\text { 8. Instituições para fazer com que as políticas } \\
\text { governamentais dependam de eleições e de } \\
\text { outras manifestações de preferência. }\end{array}$ \\
\hline
\end{tabular}

Neste processo, destaca-se que qualquer falta sobre o direito de exercer oposição o direito de participar é tolhido de parte do significado, quando comparado a um país onde se possibilita a contestação pública. Assim, desenvolver um sólido sistema de contestação pública é imprescindível para a existência da democracia. Todavia, é importante frisar que esse sistema não significa necessariamente equivalência à democratização plena (DAHL, 1997). 
Uma das preocupações de análise de Dahl (1997) são os efeitos e as influências que os acessos e controle dos recursos socioeconômicos podem ter sobre os recursos de poder. Diante dessa configuração, o pluralismo societal passa a ser uma categoria de determinação sobre a democracia, pois quanto mais plural for uma sociedade mais os recursos de poder são distribuídos em grupos e, por consequência, menor a possibilidade de um único grupo ter acesso hegemônico sobre esses recursos, tendo, por conseguinte, maior dificuldade de exercer preponderância sobre os demais. Nesta esteira, é preciso considerar que o desenvolvimento econômico contribui para o aumento do pluralismo societal.

De outra forma, Dahl (1997) destaca que quando regimes hegemônicos e oligarquias competitivas se deslocam na direção de uma poliarquia, estrutura-se um campo de aumento de oportunidades, de participação efetiva e contestação, onde indivíduos e/ou grupos podem expressar suas preferências, sendo levadas em consideração nas decisões políticas. Todavia, o autor destaca que transformações que possibilitem maior oportunidade de contestação dos opositores do governo refletem maior possibilidade de conflitos.

Em decorrência desse processo, quanto maior for o conflito entre governo e oposição, maior será o esforço das partes na busca por negar as oportunidades de participação para o outro nas decisões políticas de relevância e expressão, tornando mais improvável a tolerância entre os grupos (DAHL, 1997).

Para tanto, Dahl (1997, p. 36-37) apresenta algumas leituras possíveis de desdobramento desse conflito indicando três axiomas: no primeiro, temos que a probabilidade de um governo tolerar uma oposição aumenta com a diminuição dos custos esperados da tolerância; no segundo, a probabilidade de um governo tolerar uma oposição aumenta na medida em que crescem os custos de sua eliminação; e, no terceiro, quanto mais os custos da supressão excederem os custos da tolerância, tanto maior a possibilidade de um regime competitivo.

Neste sentido, quanto menor forem os custos de tolerância, maior a segurança do governo; quanto maior forem os custos de supressão, maior a segurança da oposição. Destarte, a criação e a manutenção de oportunidades mais amplas para as oposições contestarem um governo estão baseadas em condições que proporcionam um alto grau de segurança mútua para governo e oposições (DAHL, 1997). 


\section{ALFIO MASTROPAOLO: A DEMOCRACIA COMO INVENÇÃO HUMANA IMPERFEITA}

Mastropaolo (2012) apresenta que o termo democracia é permeado de diversos sentidos, sendo difícil apresentar uma definição. Contudo, podemos entender que a democracia é, em termos gerais, uma forma de exercício de poder e sua legitimação.

A democracia também não pode servinculada ao destino da humanidade, sendo, pois, mutante e fadada a um fim. Além disso, por ser uma obra humana, a democracia possui limitações, não devendo ser os problemas por que passa atualmente motivo de graves preocupações, mas sim visto como possibilidade de reorganização entre teoria e prática (MASTROPAOLO, 2012).

De acordo com Mastropaolo (2012), a democracia atualmente está permeada por uma tensão no seu sentido. Por um lado, temos aqueles que entendem que ela deve se resumir a procedimentos (regras do jogo) e por outro, aqueles que defendem uma visão mais substanciosa.

Outro ponto de importante definição trabalhado pelo autor é o da democracia basear-se em duas abstrações: o povo e a representação. Nessa esteira, pontua que os governos democráticos representativos se deparam com barreiras impeditivas de abuso do exercício do poder, mas não se pode perder de vista que em determinados momentos os representantes podem ceder à tentação de impor sua posição e visão de mundo (MASTROPAOLO, 2012).

Alves (2013), em análise da obra pontua que:

\footnotetext{
"Isso mostra o quão ingovernáveis, imperfeitos, incompletos e híbridos são os regimes democráticos. Talvez esta seja a causa de sua sobrevivência e assim, a democratização total é um pleito, mas sua concretização é muito difícil e torna-se mister voltar o olhar para os locais nos quais, e sob quais formas a democracia é exercida ou não" (MASTROPAOLO, 2012, apud ALVES, 2013, p. 226).
}

A despeito das barreiras impeditivas existentes, para Mastropaolo (2012) a distância entre representados e representantes, o qual a democracia se propõe a encurtar ou até mesmo extinguir, permanece e ainda é grande. Contudo, é importante observar que mais do que uma destruição da política vivencia-se um movimento de reconstrução. 
Nessa reconstrução os critérios midiáticos não apenas têm colocado a política em pauta, mas tem tido a capacidade de moldá-la (ALVES, 2013, p. 229).

A abertura para novos atores políticos, nesse processo, é sempre feita de forma controlada e segura, onde os antigos tomam todo o cuidado para não perderem seus privilégios e, para tanto, lançam mão de um estruturado processo de cooptação. De outra forma temos que ter a compreensão que:

\begin{abstract}
"O campo político é, ao mesmo tempo, um efeito sociológico, uma restrição e uma fonte para os políticos, já que tanto na teoria quanto na prática, a representação requer confiança e identificação. Dessa forma, o posicionamento de que há problemas com a democracia é fruto da dificuldade dos agentes políticos em lidar com essa situação, o que tenciona a representação, na medida em que os partidos fazem esforços para incluir mulheres, minorias linguísticas, etc. em detrimento de formas tradicionais de representação e de atores tradicionalmente representados" (MASTROPAOLO, 2012, apud ALVES, 2013, p. 231).
\end{abstract}

Outro ponto de preocupação destacado por Matropaolo (2012) é a grande quantidade de recursos financeiros necessário para a realização das campanhas eleitorais. Como desdobramento desse processo, o efeito imediato tem sido um constante aburguesamento das elites partidárias, distanciando das classes trabalhadoras.

De acordo Mastropaolo (2012) a democracia deve ser entendida como uma forma de exercício do poder pelo povo, e mesmo com todos os paradoxos presentes nesse exercício não se pode dizer que a democracia se esgotou. Mas sim, podemos entender que democracia mudou e nem sempre os seus resultados têm sido benéficos.

\footnotetext{
“A relação entre política e democracia é intrínseca e, portanto, a forma da primeira é o resultado de uma luta por poder e também de um amálgama entre condições culturais e econômicas. Assim, é preciso questionar se o uso do termo democracia que se faz contemporaneamente quer dizer continuidade ou ruptura, sendo necessário ainda, atentar para as desigualdades presentes hoje" (MASTROPAOLO, 2012, apud ALVES, 2013, p. 232).
}

Por fim, Mastropaolo (2012) aponta que ainda que sujeita a ser contestada diante de crises econômicas, política e de representatividade, a democracia deve persistir. Pois, não perdendo de vista que a democracia é uma invenção imperfeita, com base em abstrações, ela se coloca com valores fortemente contrários a todas as formas de autoritarismo e arbitrariedade.

Assim, ao primeiro passo de sua desagregação é preciso juntar forças para reagrupar as condições do seu exercício, permitindo a permanência da cultura dos 
direitos. Deste modo, temos como tarefa enfrentar os desafios e buscar sempre compreender melhor os pactos, interesses e agentes envolvidos, de modo a desvendar posicionamentos egoístas e redirecionar forçar para o desenvolvimento do Estado de Bem-Estar Social (MASTROPAOLO, 2012).

\section{SIMON SCHWARTZMAN: CORRUPÇÃO E COESÃO SOCIAL NA ANÁLISE DA DEMOCRACIA}

Para Schwartzman (2008), existe uma percepção de que a corrupção acontece de forma generalizada na América Latina, afetando a vida dos cidadãos nas esferas políticas, econômica, pública e mesmo privada. De maneira objetiva, é possível afirmar que a corrupção afeta a coesão social nos países da região, de diferentes formas.

Em contrapartida, aponta o autor: "uma das características fundamentais de um sistema social coeso é a legitimidade de suas instituições públicas" (SCHWARTZMAN, 2008, p. 03).

Contudo, na América Latina até os anos 80 prevalecemos regimes autoritários, estando sempre acompanhado de elevados níveis de corrupção. Os regimes autoritários contribuem com a corrupção, dentre outros motivos, pelo cerceamento da liberdade de expressão, retirada da autonomia do poder judiciário e uso discricionário do poder concentrado apenas no poder executivo (SCHWARTZMAN, 2008).

Quanto aos regimes corruptos, eles têm sempre uma tendência ao autoritarismo, pois não convive de forma harmoniosa com a liberdade de imprensa, com um poder judiciário autônomo e com o livre exercício das oposições (SCHWARTZMAN, 2008).

O conceito mais difundido de corrupção é o de "uso indevido de posição pública para a obtenção de ganhos privados" (SCHWARTZMAN, 2008, p. 5). Uma das consequências, sendo um forte consenso entre os economistas,é que a corrupção age negativamente sobre a economia de um país.

\footnotetext{
"Quando os governantes tomam decisões em função dos pagamentos privados que recebem, nem sempre são as formas mais eficientes e competentes que aceitam investir no país, e, quando o fazem, cobram um prêmio extraordinário pela incerteza a que estarão submetidas, seja na forma de isenções de impostos, monopólios, preços administrados, ou outros. Muitas firmas preferem não investir nestas condições, e outras privilegiam
} 
investimentos especulativos, de curto prazo, em detrimento de projetos de longa duração e maturidade" (SCHWARTZMAN, 2008, p. 6-7).

Assim, se o suborno das autoridades é uma prática corriqueira, na outra ponta, como consequência, temos que impostos deixarão de ser coletados, e se beneficiarão dos serviços públicos apenas aqueles que têm condições de pagar por fora o que necessitam. Esse movimento traz prejuízos a investimentos públicos de interesse geral, como saúde, educação, infraestrutura, etc.

Segundo Schwartzman (2008), ainda é preciso atentar para um tipo específico de corrupção muito prejudicial à coesão social. Trata-se da corrupção especificamente política, que ocorre quando as "regras do jogo" são violadas, tanto nos processos eleitorais quanto no funcionamento das instituições governamentais.

Se o processo eleitoral depende estruturalmente de financiamento privado de campanha dos candidatos, conluios entre estes e grupos financeiros e empresariais se tornam prática corriqueiras. Com isso, é perceptível que os financiadores recebem benefícios bastantes tangíveis (SCHWARTZMAN, 2008).

Considerando o Brasil como um exemplo, onde a ação do executivo depende de negociações permanentes com o congresso para aprovação de leis, Schwartzman (2008, p. 9) pontua que, nestas condições, "a barganha por cargos, votos e liberação de verbas torna-se também quase inevitável".

A corrupção dessa natureza está relacionada com a cultura ética de cada sociedade, mas depende também, em grande parte, de como as instituições políticas estão formatadas, da transparência dos processos políticos e da ação governamental, bem como da força da opinião pública e da independência tida pela imprensa. Diante desse quadro, para o autor:

\footnotetext{
“[...] o funcionamento adequado do regime democrático supõe que os processos eleitorais sejam transparentes e resistentes à fraude, que existam instituições governamentais permanentes, que a administração pública se exerça de forma profissional, que o judiciário seja independente em suas decisões, e assim por diante. A imprensa e a opinião pública, nos regimes democráticos, têm a função essencial de explicitar aquilo que é o interesse geral da sociedade, e desta forma colocam limites nas tendências ao arbítrio que são frequentes no exercício do poder" (SCHWARTZMAN, 2008, p. 9).
}

A democracia deve ser concebida como um sistema que formaliza, regula e, sobretudo, legitima o poder, protegendo as minorias e garantindo a participação de todos os setores da sociedade nas disputas eleitorais. Além disso, a mesma importância 
que a legalidade formal dos processos políticos e eleitorais tem deve ser dada a legitimidade e o reconhecimento que o sistema político recebe da sociedade.

Além de legitimar essa ordem política a democracia se incumbe de criar mecanismos de administração e solução de disputas, trazendo os conflitos para um campo salutar de estabilidade das instituições (SCHWARTZMAN, 2008).

Diante dos processos históricos de formação de diversos países da América Latina e, particularmente, do Brasil, Schwartzman (2008) ressalta que não se pode esquecer o traço comum modernizador experimentado, qual seja, a "modernização conservadora". Esse tipo de modernização garantiu a concentração dos benefícios da expansão e desenvolvimento econômico em um número restrito de pessoas.

Como consequência desse modelo de modernização, tem-se uma intensa limitação de grande parcela da população de participar ativamente da vida econômica, social e política. Também conhecidas como sociedades patrimoniais, para funcionar ao longo do tempo, sociedades com essas marcas desenvolveram complexos sistemas de leis, instituições e tradições que promovem arbítrio inclusive no poder central, facilitando, assim, práticas de corrupção por parte dos seus atores.

Ainda é preciso observar que as normas de funcionamento dos mercados estão em constante conflito e competição com outras normas e valores. Não obstante, é preciso que o mercado seja regulado por normas compatíveis com os interesses racionais dos seus participantes (SCHWARTZMAN, 2008).

Um traço característico das sociedades em que prevalece a corrupção é o pouco desenvolvimento econômico, desigualdade exacerbada, falta de transparências nas instituições, precário funcionamento das leis, instabilidade e imprevisibilidade da postura das autoridades públicas e instituições públicas com baixa legitimidade.

\footnotetext{
“A corrupção está associada à perda generalizada de confiança das pessoas nas instituições e valores coletivos, que tem como consequências seja a anomia individual, seja a fragmentação da sociedade em grupos e seitas isoladas, ou uma combinação das duas coisas" (SCHWARTZMAN, 2008, p. 27).
}

Por óbvio que a corrupção não é a causa determinante de todos os problemas do subdesenvolvimento, desigualdade, fragilidade das instituições e outras mazelas de uma sociedade, mas é certa a associação dos seus efeitos a eles. 
Para Schwartzman (2008), ainda que não exista uma medida determinante para acabar com a corrupção, algumas ações podem ser empregadas com efeitos significativos na sua minoração, tais como que se destinam a liberdade de imprensa e opinião, a reformar o Estado, o sistema político-eleitoral e o judiciário, bem como a garantia de transparência, pluralismo e fortalecimento da sociedade civil e o desenvolvimento da educação e das profissões.

\section{AFINAL, O QUE É DA DEMOCRACIA?}

Diante das reflexões e análises dos autores, compreende-se que é fundamentalmente depositado à democracia, por ser obra humana, aspirações de diversos significados, interesses, intensões e paixões.

Como podemos ver em Dahl(1997), considerando que a experiência humana não chegou perto do ideal democrático, o que até hoje se desenvolveu não pode nem mesmo ser chamada de democracia, mas sim poliarquia, no sentido de quea democracia é um projeto inacabado. De toda forma, não é possível conceber a existência de um período ondese encontre as condições para a plena realização da democracia ideal.

Em Mastropaolo (2012), há o entendimento que, mesmo sendo difícil chegar a uma definição do que seja democracia, podemos dimensiona-la como forma de exercício de poder e sua legitimação. Ao mesmo tempo, alerta que não se pode perder a historicidade do seu processo e, assim como outros fenômenos sociais, produto da ação humana, ela é imperfeita e fadada ao fim. A crise que assola as suas bases não deve ser vista com temor, mas sim como tempos de oportunidade para sua modificação.

Neste conjunto, pode-se afirmar que a democracia é um fato histórico que, portanto, tem começo, meio e em algum momento terá um fim. Uma de suas principais características é garantir e legitimar o exercício do poder, estando, invariavelmente, nesse processo histórico, permeada por crises.

Jáem Schwartzman (2008), como destacado anteriormente, a democracia pode ser compreendidaem constante interação com outros fatos e fenômenos sociais, contribuindo diretamente para a agregação ou desagregação de um Estado. Nesta perspectiva, é essencial a democracia proteger as minorias, garantir a participação de todos nos espaços políticos e proporcionar ambiente que contribua com o bom 
relacionamento das instituições. O quanto de corrupção e coesão social presentes em uma sociedade, corresponde o quanto de democracia ela tem, ou vice-versa.

Podemos destacar que em todos os autores há a concordância de que a liberdade é um princípio fundamental para a existência da democracia, diferenciando-a dos regimes autoritários. Cabe atribuir àliberdade um valor ético central nas relações humanas democráticas. A noção de justiça e igualdade são princípios que também permeiam os pressupostos e valoração da democracia.

Outro traço comum nas reflexões e análises dos autores é a nítida compreensão que os limites e possibilidades da democracia estão relacionados à temporalidade. Os motivos de inflexão, para tanto, podem ser políticos (regime representativo presidencialista ou parlamentarista, com maior ou menor organização e participação da população nas esferas de decisão), econômicos (país subdesenvolvido ou desenvolvido) ou mesmo cultural (mais ou menos conservador, patrimonialista etc.) e social (organização tribal, por castas e/ou classes).

\section{CONSIDERAÇÕES FINAIS}

As potencialidades que a democracia propicia são muitas, porém, em seu processo histórico, por ser uma obra humana, é perceptível que as limitações também o são. A despeito das limitações e fragilidades dos regimes democráticos experimentados, é inegável que o essencial da democracia corresponde a valores de alta expressão.

Esse mesmo processo histórico, quando analisado, nos mostra que quanto mais próximos uma sociedade leva suas práticas sobre os princípios da democracia tanto maior é a justiça, liberdade e igualdade gozada pelo seu povo. Portanto, mais presente se torna o bem comum.

$\mathrm{Na}$ outra ponta, quanto mais distante se sustenta uma sociedade dos princípios democráticos, incluindo neste escopo, as que vivem sobre a aparência da democracia, maior o autoritarismo, desigualdade e injustiças presentes. Portanto, mais presente é o exercício do poder em benefício de poucos, sustentando um regime de privilégio (de uma minoria) em detrimento de direitos (de uma maioria).

De toda forma, não se pode elevar a democracia a um status de entidade solucionadora de todos os problemas humanos, sob pena de adentrar num labirinto sem 
saída. Mas entender que, com todos os problemas e contradições, característica ao que é humano, ela é expressão do que melhor já se produziu em termos de organização social.

O tempo de duração e permanência (ou não) de determinadas características de um regime democrático, com mais ou menos representatividade, mais ou menos participação, se deve a mínima correspondência aos anseios e necessidades do povo, agende último que lhe dá sustentação.

Por fim, pode-se inferir que o povo deve ser parte da construção para que um regime seja caracterizado como democrático e, em especial nesse processo, compreender que a democracia longe de ser uma obra acabada, de ter se esgotado, está em constante modificação, portanto, inacabada.

\section{BIBLIOGRAFIA}

ALVES, G. B. A democracia tem causas perdidadas? Revista Tempo da Ciência, Volume 20, $\mathrm{N}^{\circ}$ 40, UNIOESTE, 2013. Disponível em: <http://erevista.unioeste.br/index.php/tempodaciencia/article/view/10056>. Acesso em: 01 de jul. 2017.

DAHL, R. A. Poliarquia: participação e oposição. Tradução de Celso Mauro Paciornik. São Paulo: Editora da Universidade de São Paulo, 1997.

MASTROPAOLO, A. Is democracy a lost cause? Paradoxes of an imperfect invention. Colchester: European Consortium for Political Research Press, 2012.

SCHWARTZMAN, S. Coesão social, democracia e corrupção. São Paulo: iFHC/CIEPLAN, 2008. Disponível em: <fundacaofhc.org.br/files/papers/446.pdf>. Acesso em: 05 de jul. 2017. 